\title{
Caminhos para construção de territórios psicossociais: contribuições ao debate
}

\author{
Pathways to construction of psychosocial territories: contributions \\ to the debate
}

\author{
Caminos para la construcción de territorios psicosociales: \\ contribuciones al debate
}

SAÚdE MENTAL PARA A ATENÇÃo BÁSICA. Soalheiro N, organizadora. Rio de Janeiro: Editora Fiocruz; 2017. 249 p. ISBN 978-85-7541495-8.

doi: 10.1590/0102-311X00152718

A mudança do modelo de atenção em saúde mental, que foi impulsionada pelo movimento da Reforma Psiquiátrica nos anos 1970 e alçada à política de Estado com a Lei no 10.216, em 2001, é ainda um processo em construção. A transformação radical nos modos de acolher e cuidar de pessoas em sofrimento psíquico nos seus territórios de vida - mandato público, que sintetiza a responsabilidade política, clínica e ética da atenção psicossocial -, vem sendo tecida com ousadia pelos operadores do cuidado, em parceria com usuários e familiares, e tem alcançado avanços reais ${ }^{1}$. Porém, ao mesmo tempo, tornam-se cada vez mais claros os enormes desafios ainda existentes para que este país encontre o caminho seguro de construção de "territórios psicossociais", onde o cuidado colaborativo e corresponsável permita superar barreiras de acesso, qualificar a atenção e ampliar possibilidades de pertencimento social para todos.

Nesse contexto de desafios para a saúde mental comunitária, agravado pelo trágico cenário de desconstrução das políticas democráticas e sociais 2 depois do golpe parlamentar de 2016, que configura o momento atual brasileiro e incide diretamente sobre o Sistema Único de Saúde (SUS), o livro Saúde Mental para a Atenção Básica, organizado por Nina Soalheiro, com a contribuição de diferentes autores, é uma produção não apenas relevante, mas pode ser tomada como um ato de resistência. Com base na premissa de que a saúde mental não se reduz a uma área de especialidade técnica (mesmo que opere intervenções específicas), constituindo um saber transversal a diferentes campos e com potencial de contribuir para o melhor acolhimento e cuidado de usuários das redes de atenção, os autores que integram esta coletânea se debruçam sobre temas cruciais, só visíveis por meio do consistente processo de territorialização que marcou a atenção básica e a saúde mental nas últimas duas décadas. Dessa forma, questões como as do envelhecimento e experiências de desamparo, do aumento de taxas de suicídio ou de tentativas de autoextermínio, da medicalização da vida quotidiana, e outras de igual complexidade, são tratadas com o esforço de fazer dialogarem teoria e prática, na busca da construção de um conhecimento fundamentado e útil às transformações reais que o SUS e suas políticas são chamados a realizar.

O livro, originado de uma investigação desenvolvida em territórios plenos de iniquidade na cidade do Rio de Janeiro - como os de Manguinhos e do Complexo do Alemão -, sob a coordenação da organizadora, é também resultado da percepção dos pesquisadores sobre uma distância significativa entre o universo das pesquisas 
e a vida vivida nas práticas territoriais, com seus impasses e desafios concretos. O objetivo, registrado na Apresentação, foi o de oferecer às equipes de saúde a sistematização de conceitos que possam tornar-se ferramentas de renovação das práticas de cuidado de pessoas que vivem experiências de sofrimento psíquico e, ainda, o de "trabalhar diversas temáticas da saúde mental que possam interessar aos profissionais da atenção básica de uma forma acessivel, mas mantendo sua complexidade” (p. 17). Nessa via, os conceitos de território, qualidade de vida, promoção de saúde, redução de danos e processos de trabalho - debatidos em capítulos específicos por autores de diferentes formações - constituem os alicerces teóricos que sustentam o diálogo com os trabalhadores da prática clínica e pesquisadores do campo.

O fio condutor das argumentações e propostas de ação é a desinstitucionalização, conceito fundante da saúde mental comunitária. Na coletânea, há uma releitura desse conceito, destacando sua perspectiva transversal, capaz de impulsionar o cuidado em liberdade, em instituições abertas, com trabalho coletivo, que buscam uma nova conexão entre a dimensão subjetiva e a dimensão social na compreensão dos padecimentos humanos e na construção de estratégias de cuidado.

Outra contribuição que o livro organizado por Nina Soalheiro traz diz respeito à produção de conhecimento em saúde mental para o SUS, em que metodologias diversificadas de investigação são acionadas para dar conta de indagações concretas e cruciais, próprias do dia a dia das comunidades assoladas pela violência urbana e pela iniquidade. No caso da saúde mental, os caminhos tradicionais da pesquisa em psiquiatria e psicologia não são efetivos para construir um mapeamento útil dos desafios da clínica no território, com suas incertezas e volatilidade, com a presença constante dos limites impostos à condição cidadã de usuários e trabalhadores. Urgem metodologias inovadoras que, como apontado por Delgado ${ }^{3}$, possam construir percursos que enfrentem os desafios reais e concretos da vulnerabilidade social e das intervenções psicossociais complexas, que colocam lado a lado a saúde mental e a atenção básica na pulsação inquietante dos territórios.

Como tarefa audaciosa e árdua, sempre incompleta para dar conta dos temas relacionados à superação da desassistência e dos descaminhos na história brasileira de cuidado de sua população, a coletânea, apesar do relevante esforço empreendido, deixou em aberto a questão da saúde mental de crianças e adolescentes (SMCA). Silenciada por décadas e apenas tardiamente incluída na agenda pública 4, a SMCA constitui ainda hoje uma dívida do Estado democrático, convocando a todos, trabalhadores e pesquisadores, a não ceder ao silêncio, ainda mais em tempos de retrocesso das conquistas sociais progressistas. São eles então, as crianças e adolescentes, sujeitos também atravessados por sofrimento psíquico, cidadãos de plenos direitos, que convidam Nina Soalheiro e seus colaboradores a seguirem adiante na construção e compartilhamento de narrativas acadêmicas que possam transformar realidades. Neste cenário incerto e cruel da vida brasileira, da saúde mental e da atenção básica em particular, este é um desafio que merece ser enfrentado.

\section{Maria Cristina Ventura Couto 1}

1 Núcleo de Pesquisa em Políticas Públicas de Saúde Mental, Universidade Federal do Rio de Janeiro, Rio de Janeiro, Brasil. cris.ventura13@yahoo.com.br

1. Jacob KS, Sharan P, Mirza I, Garrido-Cumbrera M, Seedat S, Mari JJ, et al. Mental health systems in countries: where are we now? Lancet 2007; 370:1061-77.

2. Morosini MVGC, Fonseca AF, Lima LD. Política Nacional de Atenção Básica 2017: retrocessos e riscos para o Sistema Único de Saúde. Saúde Debate 2018; 42:11-24.

3. Delgado PPG. Limites para inovação e pesquisa na reforma psiquiátrica. Physis (Rio J.) 2015; 25:13-8.

4. Couto MCV, Delgado PPG. Crianças e adolescentes na agenda política da saúde mental brasileira: inclusão tardia, desafios atuais. Rev Psicol Clín 2015; 27:17-40. 